\title{
CAMBIOS EN LA ESTRUCTURA DE LAS RENTAS PÚBLICAS DE YUCATÁN, 1850-1902*
}

\author{
MELCHOR CAMPOS GARCÍA \\ Universidad Autónoma de Yucatán ${ }^{\mathrm{a}}$
}

Changes in the Tax Structure of Yucatan, 1850-1902

\section{RESUMEN}

El artículo analiza los cambios en la estructura tributaria de Yucatán, México, durante la transición del régimen colonial a la fiscalidad liberal, de 1850 a 1902. Caracteriza sus etapas en función de la composición y el protagonismo alternativo de los impuestos directos y los impuestos indirectos en las rentas públicas. Durante los profundos cambios en la estructura económica, la tributación indirecta al consumo y los impuestos directos sobre los sectores secundario y terciario protegieron el crecimiento del sector productivo del henequén (1869-1882). Finalmente, el impuesto sobre el henequén no sustituyó a los ingresos indirectos. La modernización fiscal (1896-1902) equilibró la tributación directa de producto con los aplicados a sectores más urbanos, el secundario y las ventas del sector mercantil.

Palabras clave: estructura tributaria, impuestos directos, impuestos indirectos, liberalismo, Yucatán

* Received 23 May 2014. Accepted 16 September 2014. Agradezco a Lorgio Cobá Noh sus comentarios a mi trabajo y de manera especial a los evaluadores anónimos de la Revista por sus valiosas recomendaciones. Esta investigación se realizó con el apoyo del Centro de Investigaciones Regionales de la UADY.

a Centro de Investigaciones Regionales “Dr. Hideyo Noguchi”-Universidad Autónoma de Yucatán (UADY), Calle 61 x 66 y 68 N 525, Centro. C.P. 97000, Mérida, Yucatán (México). Correo-e: mcgarcia@uady.mx. 


\section{ABSTRACT}

The article examines the tax structure changes in Yucatan, Mexico, during the transition from colonial system to the taxation liberal, from 1850 to 1902. It characterizes their stages according to the composition and the alternative leading role of the direct and indirect taxations in the public revenues. During the profound changes in economic structure, indirect taxation to the consumption and the direct taxes on the secondary and tertiary sectors, it protected the growth of the productive sector of the henequen (1869-1882). Finally, the tax on henequen not replaced the indirect income. Fiscal modernization (18961902) balanced the direct taxation of product with the applied to more urban areas, the secondary and the sales of the commercial sector.

Keywords: tax structure, direct taxes, indirect taxes, Liberalism, Yucatan

JEL Classification: H20, H26, N96

\section{INTRODUCCIÓN}

Los nacientes estados-nación latinoamericanos tuvieron problemas a la hora de reformar bajo nuevos principios de equidad y progresividad sus sistemas fiscales heredados de la Colonia. El liberalismo propuso introducir impuestos directos que dieran una nueva base fiscal a los Estados y eliminar, o por lo menos equilibrar, la recaudación de impuestos indirectos para liberar la carga sobre el comercio. ${ }^{1}$ El itinerario de las reformas y sus resultados dependieron de las condiciones económicas, circunstancias

1 Los impuestos directos gravan una manifestación directa y duradera de la capacidad de pago del contribuyente, mientras que los indirectos lo hacen sobre manifestaciones indirectas y transitorias de su capacidad de pago (los primeros tienen menor capacidad de ser trasladados a otros contribuyentes o consumidores). Los directos pueden ser: $a$ ) reales o de producto, cuando recaen sobre las fuentes de los rendimientos; y b) personales, que grava a los contribuyentes; fijos o capitación, o según una graduación por escalas. (Comín 1966: 46-48). Para el análisis del sistema tributario real, sus principios, su importancia en sociedades preindustriales y en vías de desarrollo, así como sus limitaciones recaudatorias cuando se ha consolidado el sector terciario y secundario, ver Fuentes Quintana (1990). El modelo de Hinrichs demuestra la preponderancia de los impuestos directos en sociedades tradicionales, en tanto que los impuestos indirectos cobran mayor presencia durante la transición hacia la modernidad; pero, en las sociedades con una fiscalidad moderna, en un primer momento pueden prevalecer los indirectos del sector externo, hasta que los internos asumen mayor dinamismo y los directos tradicionales se sustituyen por modernos (sobre personas y empresas), en Hinrichs (1967). Por lo general, se asume que la etapa colonial corresponde a la sociedad tradicional y el Porfiriato, a la sociedad mexicana, que ha modernizado su economía y un sistema fiscal integrado por federación con estados y sus municipios (Carmagnani 1989: 493). La importancia de los impuestos directos durante la Colonia y el liberalismo sobre una base de mayor justicia, en Jáuregui (2006); también su caracterización en Sánchez Santiró (2009: 17-28). 
políticas y capacidades de establecer acuerdos políticofiscales. A mediados del siglo XIX, Buenos Aires estableció mayor carga fiscal directa, sin lograr una participación significativa en la recaudación. ${ }^{2}$ Cabe rescatar que los impuestos directos exceptuaron a los pequeños o «humildes» propietarios y a la clase más pobre, a quienes resulta difícil incluir como contribuyentes. ${ }^{3}$ En cambio, en sociedades con una elite criolla resistente al pago de contribuciones directas y con una población indígena mayoritaria, la tendencia fue que la tributación descansara sobre las capitaciones indígenas y otros impuestos indirectos, como en Bolivia, Ecuador y Perú. ${ }^{4}$ En éste último, el sistema impositivo dual tenía un fuerte sesgo étnico, ya que los impuestos indirectos procedentes del comercio y del consumo recaían en los blancos y mestizos, en tanto que la «contribución personal» pesaba sobre los indígenas. Los «blancos» también pagaban la tributación directa sobre la riqueza personal, las patentes por giros comerciales y otra contribución para la industria, hasta que, a partir de 1860, los ingresos patrimoniales por el guano fueron la base del Estado y permitieron abolir la capitación indígena y casi hacer desaparecer los impuestos directos de los «blancos». ${ }^{5}$ Como se verá más adelante, en algunas regiones mexicanas ese rasgo étnico de los impuestos tiene un papel importante en las decisiones de actualizar el sistema fiscal.

En el México decimonónico, los cambios de la fiscalidad y de la estructura tributaria de herencia colonial hacia la modernidad supusieron un proceso con rupturas y continuidades, ritmos y rutas diferenciadas hasta ya entrado el Porfiriato. En una visión de largo plazo sobre el crecimiento económico y los ingresos desde fines del siglo XVIII hasta el México decimonónico, Ernest Sánchez Santiró (2008) ha caracterizado los principales cambios en el sistema tributario tradicional con el predominio de los ingresos procedentes de los monopolios, la minería, el comercio y el diezmo eclesiástico, mientras que el tributo era un ramo minoritario que aportaba un $5 \%$. De 1821 a la Reforma de 1857, los impuestos directos tradicionales (tributo y diezmo) fueron abolidos; ${ }^{6}$ sin embargo, los estancos, la capitación y las alcabalas fueron de los impuestos más persistentes en la fiscalidad del siglo XIX. Sánchez Santiró concluye que en vez de los impuestos directos del régimen colonial, el Estado en su ámbito nacional y estatal "procedió a introducir con escaso éxito diversas contribuciones liberales» como el predial, las patentes y la contribución personal que gravaran a una mayor

2 5. Irigoin (2006); Santilli (2010).

3 Santilli (2010: 40, 42).

4 Abendroth (2006).

${ }^{5}$ Contreras (2006).

${ }^{6}$ En la experiencia española, la tierra como principal base de la fiscalidad del Estado se inicia con la abolición del diezmo y se imponen nuevas contribuciones directas a propiedades inmuebles y productos (cultivos y ganadería); la obra de Vallejo Pousada (ed.) (2008) analiza este proceso y el impacto de la reforma liberal de 1845. 
base poblacional. De un régimen diversificado pero equilibrado entre impuestos directos e indirectos, el régimen fiscal de la república pasó a gravar masivamente el consumo con impuestos al comercio interno (alcabalas) y externo, acompañado de deuda externa. Pero durante la República Restaurada y el Porfiriato se acentuó la dependencia fiscal de la federación y los estados hacia los impuestos indirectos del comercio exterior. Modelo que duró hasta 1896, cuando fueron removidas las aduanas internas y derogadas las alcabalas y otras contribuciones, ${ }^{7}$ y se concretó dejar en manos de las entidades la imposición de impuestos directos.

En el caso de Yucatán, el análisis de los cambios en las estructuras tributarias de las entidades es un tema pendiente a pesar de los avances de importancia. ${ }^{8}$ La región tenía su propia estructura de ingresos que dependían de su economía, de las restricciones establecidas por el régimen político y de la capacidad de su oligarquía para innovar el sistema de imposición tradicional y negociar excepciones favorables en materia hacendaria. Por su población maya mayoritaria y con un padrón por encima de los 78.000 tributarios a principios del siglo XIX, el tributo indígena fue el pilar de los ingresos fiscales durante la Coloni; pero, ante los desafíos hacendarios por la supresión del tributo durante el régimen liberal español (1811) y la suspensión del situado novohispano, desde 1814 la provincia generó una estrategia exitosa de captación de ingresos mediante los impuestos al comercio externo. Con el restablecimiento del tributo, que transitó a la época independiente como contribución personal con una base ampliada que incluyó a los no indígenas, y los ingresos indirectos del comercio, Yucatán logró la autonomía fiscal, modificando su estructura tributaria sobre dos fuentes: los impuestos directos y los indirectos, logrando que la recaudación mercantil superara a la imposición directa entre 1816 y $1820 .{ }^{9}$

En el ámbito estatal del régimen federal mexicano, las resistencias a las contribuciones directas que afectaban a las elites fueron muy similares. ${ }^{10}$

7 Sánchez Santiró (2008; 2009: 84-126). Una valoración de conjunto del sector exportador de productos agrícolas como fuente de ingresos para los estados de 1880 a 1926, en Kuntz Ficker (2014). En el periodo 1867-1911, se distingue un primer ciclo de estancamiento de la recaudación federal hasta 1878 cuando la expansión del ingreso salta por encima del techo de los 20 millones de pesos, siendo los impuestos indirectos los más consistentes. De 1884 a 1896, las contribuciones directas tuvieron un incremento moderado por la creación de nuevos impuestos sobre sueldos y salarios federales. Con la liberación de los impuestos a la exportación, a partir de 1895 hasta principios del siglo XX, en la expansión del ingreso federal fue determinante la recaudación por ingresos indirectos dependientes del comercio exterior (básicamente, la importación), en Carmagnani (1994: 215, 259-268, 327, 335).

8 Sánchez Santiró (2008: 19; 2012); Zuleta (2004 y 2006).

9 Sánchez Santiró (2012; 2009: 148, 245). Sobre el paso del tributo colonial a la contribución directa (personal), ver Serrano Ortega (2007: 95-104) y Cobá Noh (2009).

${ }^{10}$ Durante la primera mitad del siglo XIX, en las entidades con población indígena mayoritaria, como Yucatán, Chiapas y Oaxaca, rechazaron las contribuciones directas que pesarían sobre las elites; en cambio, sostuvieron la capitación y trataron de equilibrar con impuestos indirectos procedentes del comercio y el consumo. De manera similar, en otro grupo de entidades de mayor 
Durante el primer federalismo, la columna vertebral del erario yucateco fue el impuesto directo de la contribución personal, en segundo lugar se encuentran los derechos aduanales y, en menor medida, la destilación de alcohol y las alcabalas. De diciembre de 1824 a diciembre de 1825, de los 213.128 pesos de ingreso neto, la contribución personal aportó el $68 \%$, las aduanas aportaron el $14,7 \%$ y los ingresos por derechos de destilación el $9,3 \%$; poco después, en 1832, el peso específico de la contribución fue decisivo con el $60 \%$ del ingreso estatal, que creció hasta los 311.159 pesos, en tanto que los aduanales aportaron el $11 \%$, complementando con otros ramos menores el total de ese año. ${ }^{11}$ En 1841 se había equilibrado la aportación de ambos recursos. Joaquín García Rejón, en su calidad de secretario de gobierno, informó de que la Hacienda pública de Yucatán descansaba sobre dos pilares: la contribución personal y las aduanas (derechos de importación y exportación) que dependían de los acuerdos con las autoridades nacionales. ${ }^{12}$ Bajo otras circunstancias políticas, en el presupuesto de 1846 se esperaba recaudar un monto neto de 685.707 pesos con la participación del $42 \%$ de la contribución personal y del $46 \%$ de los ingresos aduanales. ${ }^{13}$ Un modelo dual en equilibrio que predominó durante la década de 1840 y antes del episodio más virulento y desarticulador de la guerra de castas, entre 1847 y $1849 .{ }^{14}$

Pero las negociaciones entre la oligarquía regional y los gobiernos nacionales celebradas durante la primera mitad de aquella centuria, con el propósito de obtener participación en los ingresos indirectos del comercio, fueron quedando en el pasado en la medida en que la federación centró su ámbito fiscal en los impuestos indirectos, descargó de imposiciones a la producción agrícola y la alcabala se eliminó en 1896. El acuerdo federal se inclinó por dejar los impuestos directos a los estados de la república. ${ }^{15}$ Durante el auge henequenero del Yucatán porfirista, el estudio de María Cecilia Zuleta sobre el impacto de ese cultivo en la fiscalidad llegó a la conclusión que de 1882 a 1910 se "consolidó un sistema mixto", donde el sector agrícola exportador "permitió la expansión de las finanzas públicas» del Estado, identificando dos momentos de incremento: 1883 y $1902-1906 .{ }^{16}$

\footnotetext{
(footnote continued)

riqueza (Puebla, Querétaro, Nuevo León y México, así como Tabasco, quizá por su reducida población indígena) se implementaron impuestos sobre bienes inmuebles, capitales y producto para complementar sus ingresos, cuyos resultados fueron poco alentadores; pero inevitable en las décadas posteriores. Un caso excepcional fue Jalisco, que introdujo impuestos directos como base del erario estatal. Serrano Ortega (2006).

11 Memorias (1826); Tesorería (1833).

12 Memoria (1841: 9, anexo 10).

13 Memoria (1846: anexo 44).

14 Una excelente narrativa sobre el estallido de la guerra de castas en 1847 hasta su desenlace a principios del siglo XX en Reed (2001). Un profundo estudio de conjunto del conflicto étnico en Dumond (2005).

15 Sánchez Santiró (2008: 18-19); Carmagnani (1989: 473); Uhthoff (2004: 132-134).

16 Zuleta (2004: 179-247; 2006).
} 
El presente estudio se propone cubrir una laguna en la historiografía de las fiscalidad estatal, profundizar en el caso excepcional de Yucatán, como ha sugerido Sandra Kuntz Ficker, ${ }^{17}$ analizando los cambios en la estructura tributaria a partir de las variaciones de los ingresos fiscales, directos e indirectos, y su participación en la renta pública, ${ }^{18}$ durante el periodo entre 1850 y 1902, que permita observar las etapas de cambio en la transición hacia la modernización. El periodo de estudio comienza marcado por los efectos de la guerra de castas (1847): la pérdida de la población indígena como base mayoritaria de la capitación y la destrucción de la riqueza patrimonial en las zonas rurales como fuentes de ingresos directos; sin embargo, dejando atrás las contingencias del día, la sociedad yucateca logró afianzar el territorio en los límites de Yucatán y Campeche, y en 1850 reorganizó una precaria Hacienda estatal en los términos del pacto federal y una economía trastocada. En las décadas siguientes, la estructura económica transitó por un profundo cambio hacia producción exportadora del henequén, que abrió una fuente extraordinaria de ingresos y permitió la imposición directa sobre producto. El periodo de estudio termina justo en el inicio de una coyuntura cumbre (1902-1906), momento en que el gobernador Olegario Molina impulsó una modernización fiscal del Porfiriato, cúspide del precio internacional de la fibra, pero de inflexión hacia su irreversible depreciación. ${ }^{19}$

Del periodo entre 1850 y 1902 se distinguen dos momentos y se abordan con dos estrategias estadísticas respectivas. De 1850 a 1862 se mide con tres muestras estáticas: 1851, marzo de 1856-marzo de 1857 y 1862 ; en cambio, el análisis de la etapa entre 1869 y 1902 es más dinámico, ya que cuenta con una serie anual de datos (a excepción del año 1879, excluido por sus vacíos en la consolidación de las cifras). La importancia de la primera etapa radica en que tendremos una base para comparar el comportamiento de los impuestos directos e indirectos a partir del restablecimiento de la República.

17 Las aportaciones del sector exportador a los ingresos fiscales de los estados en un periodo largo, comparadas a partir de cuatro mediciones: 1879-1880, 1890, 1905, 1926, demuestran que el mejor desempeño se encuentra entre los estados agropecuarios, Yucatán, Campeche, Chiapas y Tabasco, donde el primero figura como un caso excepcional de recaudación. La imposición directa en las entidades con actividades productivas de exportación tiene una fuerte incidencia en los ingresos fiscales (como Campeche, Chiapas y Yucatán), respecto a los estados mineros, sin un importante sector exportador, o de una derrama coyuntural, como el caso de Morelos y la producción azucarera entre 1902 y 1905 (Kuntz Ficker, 2014).

18 La entrada anual estaba constituida por un monto bruto integrado por diferentes ramos: rentas públicas (tributarias y no tributarias), contribuciones federales, entradas contables, préstamos, ajustes, ajenos, depósitos, etc. En este ensayo se trabaja con rentas públicas anuales. En algunos casos, las fuentes ofrecen esas cifras; pero, en otros, los datos se obtuvieron mediante simples operaciones matemáticas. A ese concepto de rentas públicas nos referiremos con los términos «renta», «ingreso» o «recurso», adjetivado con «público», «estatal» o mediante el patronímico.

19 Existe una vasta bibliografía sobre la hacienda henequenera y el auge exportador del henequén. Sobre el tema pueden consultarse García Quintanilla (1986); Joseph (1992: 58-95) y Lapointe (2008: 29-62). 
El año 1851 es significativo porque Yucatán ha realizado la división de las rentas de acuerdo al pacto federal vigente, luego de su reincorporación a la República en $1848,{ }^{20} \mathrm{y}$, para entonces, el erario estatal se había convertido en un indicador de la existencia de un gobierno y, por lo tanto, de una «sociedad regularmente organizada». ${ }^{21}$ La segunda fecha (1857) permite observar la estructura en momentos previos a las reformas liberales y, finalmente, la tercera (1862) es posterior a la Reforma y resulta destacable para medir el impacto de la separación del distrito de Campeche, lo que hace perder a Yucatán fuentes importantes de aduanas terrestres. Luego analizamos el comportamiento anual de los ingresos durante el segundo momento entre 1869 y 1902, marcado por los años inmediatos al restablecimiento de la República y la transformación económica.

\section{LA NUEVA COMPOSICIÓN DE LOS INGRESOS ESTATALES, 1850-1862}

Sobre la base del corte fiscal del año 1851, cuya renta ascendió a 195.706 pesos, ${ }^{22}$ se observa que la estructura innovada desde el régimen gaditano (contribución personal y aduanas) había sumado una nueva fuente de ingresos: los impuestos de patentes (Cuadro 1). Los impuestos directos (51\%) estaban integrados por aquellos de distribución individual (capitación y contribución personal), las patentes y, en menor medida, los impuestos a los capitales reconocidos por las propiedades. Pero, de este modelo trípode, la contribución personal estaba en la mira de las reformas liberales, de hecho la guerra de castas había repercutido en su viabilidad.

En 1845 el censo de Yucatán (sin el distrito de Campeche) ascendía a 422.403 habitantes. El padrón de tributarios se componía de 117.413 contribuyentes de capitación: 2.342 vecinos «blancos» estaban gravados con cuatro reales mensuales; 32.176 vecinos (también «blancos») y 82.895 indígenas, con dos reales mensuales, lo que arrojaba 359.265 pesos de rendimiento total al año. ${ }^{23}$ Pero, con la guerra de castas, en 1851 se estimaba

${ }^{20}$ El estudio entrelazado de los factores mercantiles, arancelarios, hacendarios y militares como variables explicativas de las cambiantes relaciones de unión-separación de Yucatán respecto a México, un fenómeno constitutivo del Estado mexicano durante la primera mitad del siglo XIX, ver Campos García (2013) y el artículo incentivador de Zuleta Miranda (1995) para el periodo 18401846.

21 Memoria (1851: 37).

22 Memoria con que da cuenta a las Honorables Cámaras del Congreso del Estado el Secretario del Despacho, en enero de 1853, BVY, XXXVIII. De la cifra ofrecida por la fuente se ha retirado un ingreso muy ocasional de contrata por caoba que ascendió a 10.500 pesos El impuesto a los capitales pesaba sobre los capitalistas o prestamistas, no sobre los propietarios de fincas; éstos pagaban el $15 \%$ de rendimientos (a partir de 1856, el registro del catastro fue base para cobrar ese impuesto directo), las patentes sobre capitales invertidos en giros, industrias y profesiones. Memoria (1851: 43). Memoria (1857).

23 Estado general que manifiesta el rendimiento de la contribución personal, Mérida, 17 de diciembre de 1843, manuscrito citado en Suárez Molina (1977: vol. 1, 99). 


\section{CUADRO 1}

COMPOSICIÓN DE LAS RENTAS Y PARTICIPACIÓN PORCENTUAL, 1851-1862

\begin{tabular}{|l|c|c|c|}
\hline IMPUESTOS & $\begin{array}{c}\mathbf{1 8 5 1} \\
\text { (Base: } \mathbf{\$ 1 9 5 . 7 0 6 )}\end{array}$ & $\begin{array}{c}\mathbf{1 8 5 6 - 5 7} \\
\text { (Base: } \mathbf{\$ 1 7 5 . 7 6 1 )}\end{array}$ & $\begin{array}{c}\mathbf{1 8 6 2} \\
\text { (Base: } \mathbf{\$ 1 2 4 . 1 4 0})\end{array}$ \\
\hline Directos: & $20 \%$ & $23 \%$ & $22 \%$ \\
\hline $\begin{array}{l}\text { Contribuciones } \\
\text { personales }\end{array}$ & $13 \%$ & $15 \%$ & \\
\hline Impuestos a capitales & $18 \%$ & $32 \%$ & $26 \%$ \\
\hline $\begin{array}{l}\text { Patentes, giros, } \\
\text { licencias }\end{array}$ & 0 & $1 \%$ & $18 \%$ \\
\hline Predial & $51 \%$ & $71 \%$ & $66 \%$ \\
\hline Sumas & $22 \%$ & $13 \%$ & $10 \%$ \\
\hline Indirectos: & $16 \%$ & 0 & $16 \%$ \\
\hline Aduanas & $38 \%$ & $13 \%$ & $26 \%$ \\
\hline Consumos & $11 \%$ & 0 & $8 \%$ \\
\hline Sumas & & & \\
\hline Varios menores & & & \\
\hline
\end{tabular}

Fuentes: Memoria (1851); Memoria (1853); Memoria (1857); Documentos (1862).

una población de 217.233 habitantes, lo que arrojaba una pérdida de más del $51 \%$ en promedio, principalmente en los distritos de mayor población indígena por las muertes y los desplazamientos hacia las zonas de refugio en el actual estado de Quintana Roo. Una década más tarde, en 1862, el porcentaje de la pérdida respecto al censo de 1845 se mantenía alto con un $48 \% .{ }^{24}$ Aun cuando más del $60 \%$ del censo general era población maya y de otras castas, sostener la recaudación de los impuestos personales fue un desafío para el gobierno estatal.

Para 1849, la cifra estimada de 66.000 pesos de ingreso en el ramo de capitación demuestra la pérdida, superior al $80 \%$, respecto a 1845 , y a pesar de haberse aprobado su abolición debido al déficit que dejaría calculado en ese mismo monto, se dio marcha atrás para sostener su recaudación con el fin de equilibrar los ingresos con los gastos. ${ }^{25}$ Pero cuando la capitación fue restablecida el 1 de noviembre de 1850, aunque su finalidad quedó atada a un gasto de pensiones militares, el gobierno modernizó el impuesto tradicional,

\footnotetext{
24 Memoria (1851: 4) y Suárez Molina (1977: vol. 1, 47-52).

25 Iniciativa (1850: 5).
} 
ya que la tasa fue variable de acuerdo con una escala de cinco grupos de contribuyentes (hombres de entre 16 y 60 años) jerarquizados de acuerdo a sus bienes, capitales o ingresos estimados. ${ }^{26}$

En 1851, los impuestos indirectos, que aportaron un $38 \%$ de las rentas, eran básicamente derechos aduanales y consumos (aguardientes y carnes); en tanto que una miscelánea de contribuciones menores proporcionó un discreto $11 \%$ de la renta estatal. A pesar de la mayor participación de los impuestos directos, cuando se observa cada ramo se puede encontrar una aportación bastante equilibrada entre ellos (ver Cuadro 1).

Las reformas implementadas en 1856 por el gobierno de Santiago Méndez estuvieron marcadas por un itinerario liberal de abandonar el impuesto directo de la contribución personal, o capitación de herencia colonial, para adoptar una «sana máxima republicana» de que todos debían contribuir «en proporción de sus riquezas» y, por la expectativa de la nueva «constitución federal [que] reservaba al gobierno federal los impuestos indirectos, y deja [ba] los directos a los estados.» ${ }^{27}$ Sobre esta agenda programática, la reforma en el sistema tributario implementado por Méndez creó el impuesto predial sobre las propiedades territoriales, urbanas y rurales; reformó los impuestos de patentes para los capitales invertidos en el sector no agrícola y para los capitales impuestos a bienes (hipotecas), y sostuvo la capitación para los que carecían de bienes conocidos, poseían capitales no mayores de mil pesos o recibían emolumentos de hasta 30 pesos mensuales. ${ }^{28}$

Méndez abolió la capitación progresiva amarrada a un gasto específico para imponer un nuevo régimen fiscal que recaudase impuestos directos a los capitales invertidos en los sectores productivos como fuentes de las rentas públicas. Las patentes gravaron los giros de capitales del sector productivo secundario y terciario: comercios, manufacturas, talleres, oficios y profesiones. A diciembre de 1857, un estimado de los capitales en giro mayores de 100 pesos ascendía a 598.803 pesos. $^{29}$

El impuesto conocido como «a capitales» se creó en 1850 enunciando gravar la renta anual de las fincas urbanas y rústicas - así como los charcos de sal- a una tasa del $15 \%$ en 1850; un lustro más tarde, se incrementó al $30 \%$. No obstante, en términos prácticos se estimó al $5 \%$ sobre la base de los

${ }^{26}$ Colección (1851: 510-512). La tasa se estableció en uno, dos, tres, cuatro y seis reales mensuales.

27 La Unión Liberal, 17 de junio de 1856.

28 La Unión Liberal, 10 y 17 de junio, 5 de diciembre de 1856. Como ya se sabe, el plazo de terminar con las alcabalas fue aplazado en enero de 1861, luego se restablecieron en abril de 1862; así, dos décadas más tarde, en 1882 , se proyectó su supresión para diciembre de 1884, pero de nuevo se prorrogó hasta su abolición definitiva en 1896.

29 De ese monto, al mercantil correspondía el 82,5\%; a los fabriles urbanos, el 6,2 \%; y a los talleres agrícolas (artesanos, corchaderos, prensas de henequén, etc.), el 11,2 \%. Memoria (1857). Sin embargo, los corchaderos y las prensas para forjar las pacas henequeneras pertenecientes a las fincas no pagaban el impuesto de patente por estar incluido en el estimativo de la propiedad. Orden del 6 de abril de 1875, en Orosa Díaz (1956: 57-58). 
valores de las fincas y los charcos de sal, a su vez también estimados por los propietarios en un padrón creado ad hoc. El padrón conformado para estimar el impuesto a capitales registraba las propiedades con valor mayor a 100 pesos. A julio de 1857, el «valor estimativo» del conjunto de aquellos bienes era de 2.239.000 pesos como base de la recaudación. ${ }^{30}$ Pronto, los funcionarios de Hacienda denunciaron que, en el caso de las fincas rústicas, los dueños de los capitales que pagaban el impuesto eran, por lo general, "pobres»; mientras que los propietarios territoriales pagaban poco o nada. ${ }^{31}$ Pero en 1856 se introdujo un cambio de la «renta» al valor del bien inmueble con la introducción del impuesto predial que gravó las fincas (urbanas y rurales) y los charcos de sal. En este último año, mientras empezaba a operar el impuesto predial, se modificaba la tasa impositiva a los capitales al 15, el 20 y el $25 \%$ a las fincas urbanas, rurales y charcos de sal, respectivamente; de manera que, en 1856, conviven la imposición directa a la «renta» de los capitales y la predial. Finalmente, en 1862, desapareció la primera y fue sustituida por la predial. ${ }^{32}$ En marzo de 1857, el padrón catastral arrojó un valor total de 4.516 .889 pesos, ${ }^{33}$ que representó un incremento mayor del $100 \%$ sobre los estimativos del formado para gravar los capitales.

La organización del ramo también requirió un primer movimiento en 1856 con el restablecimiento de la Contaduría Mayor de Hacienda. A pesar de las opiniones contrarias a mantener ciertas contribuciones tradicionales como la personal, se imponían las necesidades de arreglos hacendísticos (equiparar el ingreso y el gasto) y las dificultades de introducir nuevas imposiciones directas, como los impuestos prediales, que se comentarán más adelante. Entre marzo de 1856 y marzo de 1857 la Hacienda yucateca manejó en bruto 191.375 pesos, pero la renta pública fue de 175.761 pesos. Esta última cifra se componía del $71 \%$ de impuestos directos con el incipiente impuesto a las fincas rurales y urbanas, en tanto que los indirectos (las aduanas y las alcabalas al consumo de carnes) aportaban el complemento del $29 \%$.

Ahora, veamos de manera sinóptica el comportamiento de la renta estatal por la separación de Campeche para formar una nueva entidad de la República en 1858 y la reforma constitucional previa al Segundo Imperio. En 1862, la Tesorería General informaba de que los recursos estatales eran

\footnotetext{
30 Memoria (1857: 15-16). Decreto de 1 de noviembre de 1850, en Colección (1851: 512-516).

31 Memoria con que da cuenta a las Honorables Cámaras del Congreso del Estado el Secretario del Despacho, en enero de 1853, BVY, XXXVIII, f. 12.

32 Decreto del 30 de septiembre de 1850, Colección (1851: 471-472). Memoria (1851: 43); Memoria (1857).

${ }^{33}$ El 41,2 \% correspondía a fincas urbanas; el 57,7\%, a las rústicas; y un porcentaje insignificante, a los charcos de sal. Memoria (1857). La República Central introdujo en 1836 el impuesto nacional a las fincas urbanas y rurales valoradas en 2.855 .944 pesos las rurales y en 4.325 .751 pesos las urbanas. Estadística (1853: 286-288). Una discusión nodal en el fracaso del impuesto rural, acompañado del urbano, como pilar de las contribuciones directas del erario nacional que sustituyera las alcabalas, en Sánchez Santiró (2006).
} 
suficientes para cubrir sus egresos. Pero la renta se había reducido a 124.140 pesos por los efectos de la segregación de Campeche. ${ }^{34}$ El porcentaje de impuestos directos era del $66 \%$; el de los indirectos, del $26 \%$, y el de los ramos menores se reducía a un $8 \%$. Pero la composición se había diversificado sin que existiera un ramo predominante; de mayor a menor participación contaba con los ingresos de las patentes, la capitación, el predial y los consumos, mientras que los rendimientos de las aduanas terrestres complementaban con un $10 \%$ la pérdida de las campechanas. La guerra de castas y la separación de Campeche afectaron drásticamente la estructura del ingreso en otro pilar fundamental desde finales de la Colonia: la contribución personal. El censo de Yucatán de 1862 arrojó una población de 248.156 habitantes (47\% hombres), con una pérdida total del $41 \%$ respecto a 1846 y 72,000 de Campeche. ${ }^{35}$ Pero los montos reales de la contribución personal, que no alcanzaron los 40.000 pesos en 1856-1857 ni la estimación de ingresar más de 60.000 pesos, no son comparables con los 156.000 de recaudación del periodo independiente hasta la década de 1840 . No obstante la abolición como ingreso estatal en 1868, en los federales habría que indagar la continuidad de ese impuesto directo de carácter tradicional. $^{36}$

\section{IMPUESTOS DIRECTOS Y CONSUMOS, 1869 A 1882}

En los años inmediatos a la derrota del Segundo Imperio, ${ }^{37}$ las contingencias del momento parecieron marcar las urgencias por localizar

34 Memoria (1862: 11-12); Documentos (1862).

35 Memoria (1862).

36 Aunque la contribución personal y la capitación quedaron atrás como rentas estatales, desde 1856 la federación impuso una contribución sobre los hombres exceptuados de reclutamiento en la guardia nacional, a cambio pagarían un impuesto directo tradicional para fondos de aquella milicia. Por lo tanto, esa contribución no era parte de la renta estatal. Las cuotas las pagaban los exceptuados urbanos: clase sacerdotal, funcionarios, profesionales de la medicina, profesores y estudiantes de colegios. Colección (1882: 276).

37 El efímero Segundo Imperio centralizó la hacienda nacional y las estatales, pero sin asimilar los erarios municipales. En 1865, el monto total que manejó la administración de Yucatán fue de 956.041 pesos, compuesto del siguiente modo: 639.188 pesos de ingreso bruto (rentas y no rentas) y 316.853 pesos de remisiones de aduanas foráneas y otras instancias, depósitos, derechos de importaciones reservados para ferrocarriles y mejoras materiales, así como una suma de dineros que no formaban parte de las rentas. De modo que, del ingreso bruto, las rentas fueron de 518.389 pesos. De este dato en conjunto, el $22 \%$ procedía de impuestos directos: contribuciones sobre fincas urbanas y rústicas, aguardiente y traslación de dominio. Por lo tanto, el grueso del ingreso, con el 78 $\%$ de impuestos indirectos, descansaba sobre el comercio de importación, los consumos, los peajes, la internación, las alcabalas, el tonelaje y otros derechos aduanales. Decreto del 6 de julio de 1863, en Segura (1863: 99-102, 115). Ver también Payno (1868: 129, 555). Las cifras agregadas de las remisiones y los depósitos no permiten estimar las transferencias que llegaron de manera extraordinaria a Yucatán para la campaña militar sobre los indígenas rebeldes de Chan Santa Cruz, que comenzó ese año. Cabe destacar que, en la suma de los impuestos indirectos, no se encuentran ingresos por contribuciones personales. 
recursos para llevar a la Tesorería del Estado. Los gobiernos yucatecos de aquellos años volvieron la mirada hacia un expediente de créditos a favor de Yucatán, que databa del primer arreglo financiero del pacto federal en 1824, y la compleja relación que guardó la Tesorería yucateca con los gobiernos nacionales hasta $1864 .{ }^{38}$ Pese a los insistentes reclamos del gobierno estatal para amortizar esa deuda, que de acuerdo a su propia liquidación ascendía a cerca de un millón y medio de pesos, el poder ejecutivo de la Unión no fue receptivo a la demanda estatal. ${ }^{39}$ Pero esa hipotética fuente de recursos distaba de significar una base para sustentar la solvencia del erario estatal, y lo más que se logró fue un incremento a 50.000 pesos de la subvención federal para la guerra de castas. ${ }^{40}$

El arreglo organizativo de la recaudación fiscal para garantizar un piso de rentas públicas fue un proceso lento ${ }^{41}$ que pasó por una cierta desorganización en los ramos de ingresos entre 1870 y 1871, después de la supresión de la contribución personal. Pero en los años siguientes se configuraron tres grupos principales de rentas estatales: 1) la contribución predial, 2) las patentes de destilación, giros e industrias, y 3) los consumos. De menor importancia, se le agregó una miscelánea compuesta por varios ramos menores de ingresos (registro público de la propiedad y de hipotecas, normal superior, productos de telégrafos y otros como los rezagos de la contribución personal).

De 1869 a 1882 la renta pública pasó de 194.659 a 254.894 pesos en una tendencia de lento crecimiento acumulado del $29 \%$ (ver Cuadro 2), acorde a la lenta recuperación económica y al cambio estructural centrado en la hacienda y las exportaciones henequeneras. La renta pública correspondiente a 1869 revela que había recuperado el volumen de lo recaudado casi dos décadas atrás, es decir en la década de 1850 y antes de la formación del estado de Campeche. ${ }^{42}$

¿Cuáles fueron las características de los tres pilares de las rentas públicas? En primer lugar, fundado en 1856, el catastro era un registro de bienes inmuebles y sus valores estimados a la baja, según los cálculos ofrecidos por los propietarios de las fincas rústicas, de las urbanas y de los charcos de sal. Incluso, el registro llevó la impronta de permitir a los dueños que disminuyeran hasta dos tercios del valor de sus propiedades registradas, iniciando con un valor estatal de 4.314 .771 pesos. ${ }^{43}$ Un acuerdo tácito entre

38 Expediente (1869: 6).

39 Exposición (1868: 16). Los reclamos estatales se reactivaron con la ley nacional de amortización de la deuda interna del 30 de noviembre de 1867.

40 Mensaje (1871: 43).

41 Ver la comparación de la organización y estructura administrativa de la Hacienda entre 1884 y 1902-1906 en Zuleta (2006: 250-254).

${ }^{42}$ La renta pública correspondiente al periodo marzo de 1856-marzo de 1857 fue de 191.375 pesos; prácticamente el mismo monto que en el año de 1851. Memoria (1857).

43 El pecado original del catastro fue que, de hecho, su base fue una estimación que realizaran los propios contribuyentes del predial, y lograron un acuerdo para rebajar un tercio de esa 
CUADRO 2

RENTAS PÚBLICAS DE YUCATÁN, 1869-1882

\begin{tabular}{|l|c|c|c|}
\hline $\begin{array}{l}\text { Año } \\
\text { fiscal }\end{array}$ & Rentas & $\begin{array}{c}\text { Tasa anual de crecimiento } \\
(\%)\end{array}$ & $\begin{array}{c}\text { Tasa acumulada de } \\
\text { crecimiento (\%) }\end{array}$ \\
\hline 1869 & 194.659 & 0 & \\
\hline 1870 & 190.393 & $-2,2$ & 0,6 \\
\hline 1871 & 195.757 & 2,8 & 1 \\
\hline 1872 & 196.597 & 0,4 & 15,6 \\
\hline 1873 & 225.314 & 14,6 & 10,5 \\
\hline 1874 & 213.722 & $-5,14$ & 13,5 \\
\hline 1875 & 220.043 & 3 & 12 \\
\hline 1876 & 216.568 & $-1,6$ & 12,2 \\
\hline 1877 & 216.955 & 0,2 & 18,3 \\
\hline 1878 & 230.219 & 6,1 & 24,9 \\
\hline 1879 & & & 28,9 \\
\hline 1880 & 243.970 & $6($ Respecto a 1878$)$ & \\
\hline 1881 & 245.373 & 0,6 & \\
\hline 1882 & 254.894 & 4 & \\
\hline
\end{tabular}

Fuentes: Expediente (1869: 56); Expediente (1878: 61-68); La Razón del Pueblo, 1878-1882. Anexo 9, Memoria (1884).

Nota: el año fiscal de 1879 no se incluyó debido a la pérdida del corte del mes de diciembre.

propietarios y gobierno para la introducción de esta nueva imposición. En el segundo ramo se encuentran las rentas por patentes de aguardiente (destilación y ventas al menudeo), giros (comercio) e industrias, y, finalmente, en el tercero, las imposiciones al consumo de productos nacionales $(25 \%)$ con sus excepciones, extranjeros $(5 \%)$ y nacionalizados $(5 \%)$, consumo de harinas y la alcabala de carnes. Como se puede observar en el Cuadro 3 y en el Gráfico 2, durante la etapa de 1869-1882 en Yucatán prevaleció el modelo diversificado de rentas públicas, pero dependiente de los consumos que aportaban el $50,5 \%$ en promedio anual.

\section{(footnote continued)}

estimación, ya en sí misma por debajo del valor real de las propiedades. Memoria (1857:16). También se les concedió deducir un porcentaje de la contribución por los intereses que pagaban las haciendas hipotecadas. Decreto del 18 de enero de 1856, en Colección (1882: 264-268). Cfr. Zuleta (2004: 190-191). 
CUADRO 3

COMPOSICIÓN DE LOS INGRESOS PÚBLICOS EN YUCATÁN, 1869-1882

\begin{tabular}{|c|c|c|c|c|c|}
\hline \multirow[b]{2}{*}{$\begin{array}{l}\text { Año } \\
\text { fiscal }\end{array}$} & \multicolumn{3}{|c|}{ DIRECTOS } & \multirow{2}{*}{$\begin{array}{l}\text { INDIRECTOS } \\
\text { Consumos (\%) }\end{array}$} & \multirow[t]{2}{*}{$\begin{array}{l}\text { Aportación a la renta } \\
\text { estatal (en porcentaje) }\end{array}$} \\
\hline & $\begin{array}{c}\text { Contribución } \\
\text { predial }(\%)\end{array}$ & $\begin{array}{l}\text { Traslación de } \\
\text { dominio }(\%)\end{array}$ & $\begin{array}{c}\text { Patentes: licores, } \\
\text { comercio e industria }(\%)\end{array}$ & & \\
\hline 1869 & 14 & 5,7 & 26,47 & 34 & 80 \\
\hline 1870 & 16,4 & 6,3 & 26,5 & 47 & 96,2 \\
\hline 1871 & 18,5 & 5,6 & 26,2 & 44,25 & 94,55 \\
\hline 1872 & 15,6 & 5,4 & 22 & 53 & 96 \\
\hline 1873 & 19,3 & 4,6 & 18,4 & 54 & 96,3 \\
\hline 1874 & 11,3 & 3,4 & 17,6 & 61,7 & 94 \\
\hline 1875 & 16 & 5,7 & 23,6 & 49 & 94,3 \\
\hline 1876 & 19,5 & 4,4 & 23,1 & 46,5 & 93,5 \\
\hline 1877 & 16,6 & 4,5 & 25,5 & 49,7 & 96,3 \\
\hline 1878 & 16 & 3,4 & 18,7 & 53,8 & 92 \\
\hline \multicolumn{6}{|l|}{1879} \\
\hline 1880 & 11 & 3,6 & 19 & 55 & 88,6 \\
\hline 1881 & 12,3 & 3,4 & 20,6 & 54,7 & 91 \\
\hline 1882 & 14 & 4,3 & 19,7 & 54,6 & 92,6 \\
\hline
\end{tabular}

Fuentes: Expediente (1869: 56); Expediente (1878: 61-68); La Razón del Pueblo, 1878-1882. Memoria (1884). Nota: el año fiscal de 1879 no se incluyó debido a la pérdida del corte del mes de diciembre. 
GRÁFICO 1

TENDENCIA DE LAS RENTAS YUCATECAS, 1869-1882 (EN PESOS)

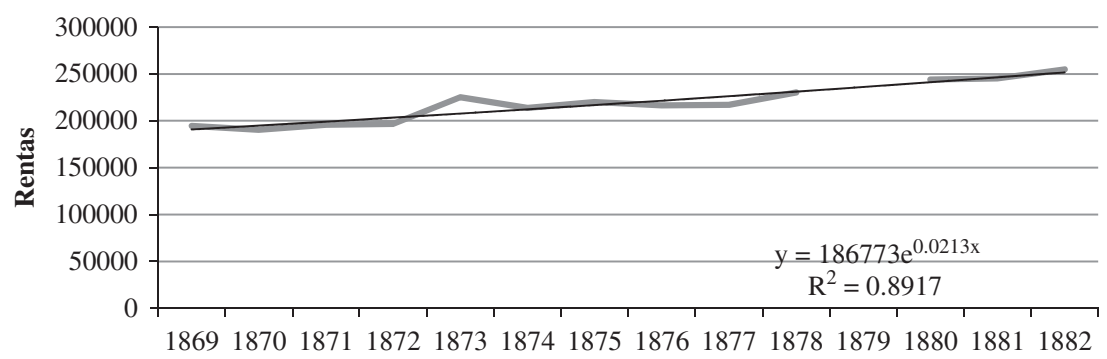

Nota: la fuente corresponde a los datos del Cuadro 2 procesados en Excel, con una línea de tendencia exponencial.

\section{GRÁFICO 2}

COMPOSICIÓN DE LAS RENTAS PÚBLICAS, 1869-1882

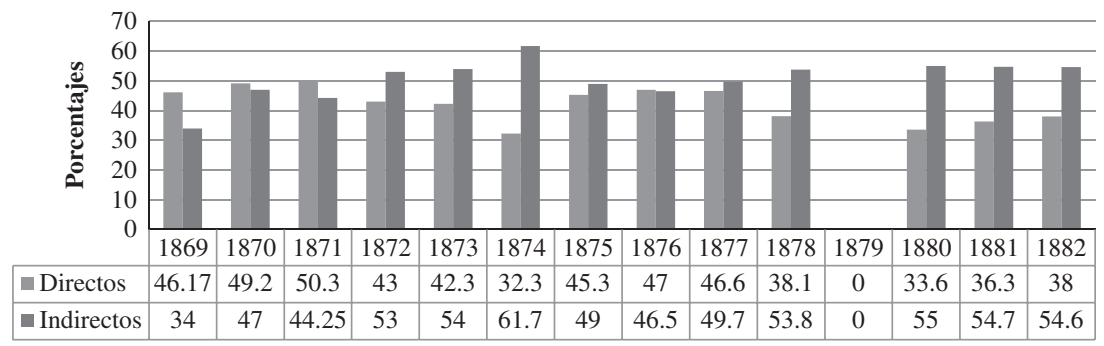

Nota: el año fiscal de 1879 no se incluyó debido a la pérdida del corte del mes de diciembre.

La participación porcentual de los tres principales rubros de rentas durante el periodo 1869-1882 demuestra que, mientras la recaudación de consumos y alcabalas incrementaba su aportación a la masa de rentas anuales, decrecía la contribución porcentual de los recursos procedentes de los impuestos directos: contribución predial, derechos de traslación de dominio y captación sobre fábricas de licores, giros mercantiles e industriales. Como también se observa en el Cuadro 3, los impuestos predial y de traslación de dominio juntos tienen una tendencia a disminuir su participación en la medida en que inician los años del auge henequenero a finales de la década de 1870. Las propiedades localizadas en la franja fronteriza con el territorio dominado por los mayas rebeldes estaban exentas, pero en 1870 esa concesión fue compensada con un ajuste hacendario por decreto que 
incrementó en un tercio el valor de las fincas sujetas a contribución. ${ }^{44}$ Sin embargo, en las manifestaciones de 1878, hubo una disminución de los valores $^{45} \mathrm{y}$, en consecuencia, una menor recaudación, como también demuestra el Cuadro 3. En este periodo, el problema del catastro consistía en un subregistro de los valores de las propiedades rurales y urbanas, así como en el derecho de traslación de dominio que prácticamente era evadido. A pesar del repunte de la recaudación estatal en 1873, que superó el techo de los 200.000 pesos con un incremento momentáneo, la velocidad del crecimiento fue lenta hasta 1882.

De manera que, a comienzos de la década de 1880, el reto del gobierno consistía en encontrar otra fuente de impuestos directos menos contencioso que la contribución predial para compensar los crecientes egresos y cubrir los compromisos del gobierno de mejoras materiales. La nueva contribución debía abandonar también las características de los impuestos indirectos. Así que, el 28 de noviembre de 1882, el Congreso yucateco aprobó una contribución de tres centavos por arroba de fibra de henequén y cobrable cuando se introdujera en Progreso, el puerto de exportación del filamento al mercado exterior e interior. En el momento de la nueva imposición, el crecimiento acumulado de la exportación a partir de 1880 era del $34 \%$ y, en 1883 , se incrementó un $34,7 \%$ respecto al año anterior.

\section{IMPACTO FISCAL DE LA CONTRIBUCIÓN HENEQUENERA, 1883-1902}

La base gravable del impuesto a la producción del henequén fue la rama o fibra producida. A partir de 1883, la unidad de medida fue la arroba $(11,5 \mathrm{~kg})$, por la que se pagaban 3 centavos; y en 1896 cambió al pago de 27 centavos por cada $100 \mathrm{~kg}$. Hubo un incremento del peso fiscal sobre la producción porque el cambio favorecía al erario en unos céntimos; sin embargo, a efectos de las comparaciones estadísticas, ambas tasaciones resulta indistintas, por lo que se ha decidido tomar como medida los kilos de producto exportado.

¿Cuánto produjo el impuesto henequenero de 1883 a 1902? ¿Cuánto creció la renta pública? El Cuadro 4 relaciona los montos anuales de renta pública y los rendimientos del gravamen, sin los impuestos correspondientes a la federación para tener una mejor apreciación de la participación del impuesto estatal en las rentas yucatecas. ${ }^{46} \mathrm{La}$ recaudación significó el

44 Decreto 64, Mérida, 5 de abril de 1870, en Leyes (1875: 11-12).

45 El Eco del Comercio, 20 de abril de 1880.

46 Los porcentajes del impuesto difieren de los ofrecidos por Zuleta, que incluyen el $30 \%$ correspondiente a la federación. Cfr. Zuleta, (2006: 284; 2004: 227). La federación impuso a los contribuyentes un $25 \%$ sobre los enteros recaudados en las entidades, y en 1892 se elevó al $30 \%$. Además, un derecho federal de 60 centavos por cada $100 \mathrm{~kg}$ de rama exportada y por estampillas a las facturas de ventas, a razón de 6 pesos por millar. En suma, un 7 \% del precio de la exportación. Boletín de Estadística, 16 de diciembre de 1894. 
CUADRO 4

APORTACIÓN DEL IMPUESTO A LA RENTA ESTATAL EN PESOS, 1883-1902

\begin{tabular}{|c|c|c|c|}
\hline Años & Renta Pública & Impuesto henequenero & Porcentaje \\
\hline 1883 & $385.624,33$ & 93026.3 & 24,12 \\
\hline 1884 & $374.466,55$ & 96242.49 & 25,7 \\
\hline 1885 & $441.485,53$ & 112787.84 & 25,54 \\
\hline 1886 & $452.055,39$ & 101321.52 & 22,41 \\
\hline 1887 & $501.450,74$ & 97157.4 & 19,37 \\
\hline 1888 & $483.796,43$ & $96.744,1$ & 20 \\
\hline 1889 & $510.634,5$ & $96.821,08$ & 19 \\
\hline 1890 & $498.162,7$ & $102.237,56$ & 20,5 \\
\hline 1891 & $587.186,14$ & $130.797,4$ & 22,27 \\
\hline 1892 & $621.697,75$ & $148.834,92$ & 24 \\
\hline 1893 & $637.749,04$ & $148.799,94$ & 23,3 \\
\hline 1894 & $680.900,99$ & $161.601,91$ & 23,7 \\
\hline 1895 & $696.202,6$ & $167.096,99$ & 24 \\
\hline 1896 & $682.920,14$ & $161.173,9$ & 23,6 \\
\hline 1897 & $699.774,02$ & $190.289,88$ & 27,2 \\
\hline 1898 & $769.730,14$ & $199.969,68$ & 26 \\
\hline 1899 & $820.852,03$ & $190.292,3$ & 23,2 \\
\hline 1900 & $837.231,06$ & $201.387,62$ & 24 \\
\hline 1901 & $862.034,2$ & $217.531,83$ & 25,23 \\
\hline 1902 & $1.010 .274,9$ & $232.361,25$ & 23 \\
\hline
\end{tabular}

Fuentes: Anuario (1896: 697), Reseña (1899); Reseña (1900); Reseña (1901); Memoria (1884); Memoria (1885); Boletín de Estadísticas, 1894-1903; La Razón del Pueblo, 1880-1901; AGEY, Congreso, 1885, 1887, 1888,1895 y 1896.

24,12\% para 1883 y osciló entre el $19 \%$ de 1889 (año de menor aportación) y un máximo del $27 \%$ en 1897. En promedio, aportó un $24,5 \%$ de la renta estatal.

Debido a la característica fiscal del impuesto a la producción de la fibra, la recaudación siguió el comportamiento del volumen comercializado en el 
GRÁFICO 3

EXPORTACIÓN HENEQUENERA Y RECAUDACIÓN, 1883-1902

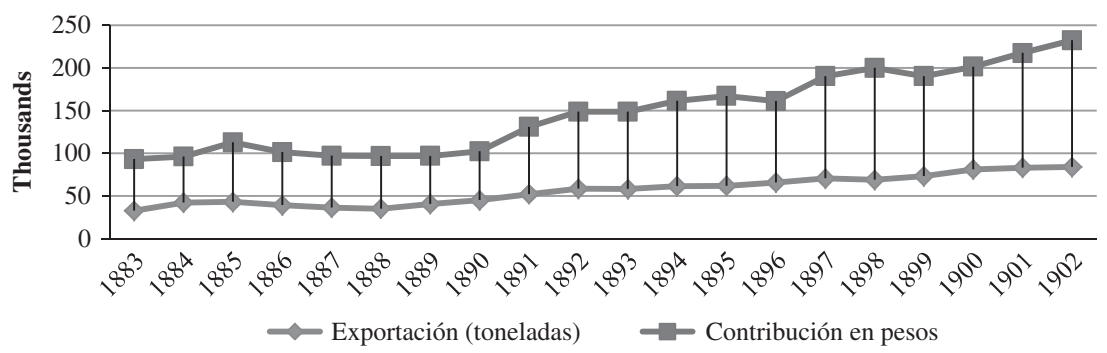

Fuente: Askinasy (1936); Boletín de Estadística, 1 de junio de 1902, 1 de mayo de 1904 y 1 de agosto de 1905; y Cuadro 4.

mercado externo y nacional (Gráfico 3), con independencia del valor de la exportación, tan variable como los precios internacionales de la fibra.

Ahora bien, las cifras anuales de las rentas públicas del Cuadro 5 para el periodo 1883-1902 muestran que en 1883 dieron un salto del 51,3\% respecto al año anterior, siguiendo una tendencia de crecimiento en la que destacan los años 1885, 1891 y 1902, por los significativos incrementos anuales del $17 \%$ en los ingresos estatales respecto a sus correspondientes años anteriores. Un crecimiento acumulado del $154 \%$ corrobora que este fue un periodo de bonanza económica.

\section{EL IMPUESTO HENEQUENERO EN LA ESTRUCTURA DE LA RENTA PÚBLICA, 1883-1902}

No obstante el crecimiento del periodo, la aportación del henequén a la renta pública del Estado fue de un $23 \%$ en promedio anual; por lo tanto, ¿hubo alguna modificación en la composición del $77 \%$ restante del ingreso público? Sin ninguna novedad que alterase «los hábitos por largo tiempo adquiridos» en materia impositiva, ${ }^{47}$ de 1883 a 1895 la contribución agrícola se sumó al modelo fiscal precedente integrado por la recaudación catastral, los consumos, las patentes y una miscelánea de ramos menores (ver Cuadro 6).

Una década más tarde, en 1896, el Estado realizó una reforma para abolir las alcabalas al consumo y estableció el libre tránsito; a cambio, impuso una nueva contribución sobre las ventas (3\% al mayoreo, $2 \%$ al menudeo y una patente para ambulantes), es decir, un impuesto indirecto a la realización efectiva de la mercancía sin los efectos indeseables de la alcabala y de los derechos al consumo. ${ }^{48} \mathrm{El}$ año fiscal de 1896 fue sui géneris, ya que durante los

\footnotetext{
47 Memoria (1886: XXVIII).

48 Zuleta (2004: 196-197; 2006: 259-260).
} 
CUADRO 5

CRECIMIENTO DE LA RENTA PÚBLICA, 1882-1902

\begin{tabular}{|c|c|c|c|}
\hline Años & Renta Pública (en pesos) & Crecimiento anual & Crecimiento acumulado \\
\hline 1882 & 254.894 & & \\
\hline 1883 & $385.624,33$ & 51,3 & \\
\hline 1884 & $374.466,55$ & $-2,9$ & 48,4 \\
\hline 1885 & $441.485,53$ & 17,9 & 66,3 \\
\hline 1886 & $452.055,39$ & 2,4 & 68,7 \\
\hline 1887 & $501.450,74$ & 11 & 79,7 \\
\hline 1888 & $483.796,43$ & $-3,5$ & 76,2 \\
\hline 1889 & $510.634,5$ & 5,5 & 81,7 \\
\hline 1890 & $498.162,7$ & $-2,4$ & 79,3 \\
\hline 1891 & $587.186,14$ & 17,8 & 97,1 \\
\hline 1892 & $621.697,75$ & 5,8 & 103 \\
\hline 1893 & $637.749,04$ & 2,6 & 105,6 \\
\hline 1894 & $680.900,99$ & 6,7 & 112,3 \\
\hline 1895 & $696.202,6$ & 2,2 & 114,5 \\
\hline 1896 & $682.920,14$ & -2 & 112,5 \\
\hline 1897 & $699.774,02$ & 2,4 & 115 \\
\hline 1898 & $769.730,14$ & 10 & 125 \\
\hline 1899 & $820.852,03$ & 6,6 & 131,6 \\
\hline 1900 & $837.231,06$ & 2 & 133,6 \\
\hline 1901 & $862.034,2$ & 3 & 136,6 \\
\hline 1902 & $1.010 .274,9$ & 17,2 & 153,8 \\
\hline
\end{tabular}

Fuente: datos del Cuadro 4.

primeros seis meses permanecieron vigentes los derechos de consumo y en el segundo semestre comenzó la nueva recaudación fiscal. ${ }^{49}$ Así que, en este periodo, se pueden distinguir dos etapas: a) de 1883 a 1895 y b) de 1896 a 1902. Respecto a la primera etapa, lo que se observa en los ramos - a excepción del

49 La ley fue promulgada el 15 de abril de 1896 por el gobernador Carlos Peón. 
CUADRO 6

APORTACIÓN PORCENTUAL DE LOS IMPUESTOS A LA RENTA DE YUCATÁN, 1883-1902

\begin{tabular}{|c|c|c|c|c|c|c|c|}
\hline & \multicolumn{3}{|c|}{ IMPUESTOS DIRECTOS } & \multicolumn{3}{|c|}{ IMPUESTOS INDIRECTOS } & \multirow[t]{2}{*}{ Suma $(\%)$} \\
\hline Años & Henequén $(\%)$ & Patentes (\%) & Propiedad raíz (\%) & Traslación & Consumo (\%) & Ventas $(\%)$ & \\
\hline 1883 & 24,12 & 16,46 & 12,5 & 2,4 & 40,5 & & 96 \\
\hline 1884 & 25,7 & 15,5 & 13 & 2,4 & 38,84 & & 95,4 \\
\hline 1885 & 25,54 & 11,74 & 10,8 & 2 & 35,16 & & 85,2 \\
\hline 1886 & 22,41 & 10,56 & 10,4 & 1,76 & 47,4 & & 92,5 \\
\hline 1887 & 19,37 & 10 & 9,3 & 2,37 & 43,13 & & 93,2 \\
\hline 1888 & 20 & 13,6 & 10 & 2,7 & 51,77 & & 98 \\
\hline 1889 & 19 & 12,85 & 7,37 & 2,7 & 50,57 & & 92,5 \\
\hline 1890 & 20,5 & 13,63 & 9,38 & 1,6 & 43,51 & & 88,6 \\
\hline 1891 & 22,27 & 10,3 & 7,16 & 1,6 & 42,26 & & 83,6 \\
\hline 1892 & 24 & 9,73 & 7,56 & 1,2 & 39 & & 81,5 \\
\hline 1893 & 23,3 & 10,32 & 9,7 & 1,6 & 41,29 & & 86,2 \\
\hline 1894 & 23,7 & 18,66 & 7,9 & 2,35 & 38,12 & & 90,7 \\
\hline 1895 & 24 & 18,13 & 7,7 & 2,66 & 36,37 & & 88,8 \\
\hline 1896 & 23,6 & 19,75 & 9,55 & 2,7 & 21,74 & 9 & 86,3 \\
\hline 1897 & 27,2 & 24,32 & 11,78 & 2,76 & 10 & 16,55 & 92,6 \\
\hline
\end{tabular}




\begin{tabular}{|c|c|c|c|c|c|c|c|}
\hline 1898 & 26 & 24,47 & 10,73 & 3,53 & 9,8 & 14,67 & 89,2 \\
\hline 1899 & 23,2 & 25,45 & 9,16 & 4,4 & 9,5 & 14,23 & 86 \\
\hline 1900 & 24 & 25,7 & 9,33 & 3,3 & 9,8 & 14,48 & 86,6 \\
\hline 1901 & 25,23 & 25,85 & 9 & 3,2 & 9,3 & 14,52 & 87 \\
\hline 1902 & 23 & 24,3 & 8,73 & 5,7 & 9,5 & 17 & 88,2 \\
\hline
\end{tabular}

Fuentes: Anuario (1896: 697), Reseña (1899); Reseña (1900); Reseña (1901); Memoria (1884); Memoria (1885); Boletín de Estadísticas, 1894-1903; La Razón del Pueblo, 1880-1901; AGEY, Congreso, 1885, 1887, 1888, 1895 y 1896. 
impuesto al henequén - fue que dejaron de contribuir porcentualmente del mismo modo que en el periodo anterior (1870-1882). El ingreso predial, aunque recuperó puntos porcentuales, tendió a disminuir su aportación a finales de la década de 1880 en torno a un $9,4 \%$ anual. ${ }^{50}$ Los consumos también perdieron capacidad de contribuir y aportar cantidades similares a las del periodo anterior (1869-1882), excepto un par de años (1888 y 1889); pero, entre 1883 y 1902, ese ramo ofreció un $42 \%$ anual de media. Por último, el ramo de patentes de licores, giros comerciales y profesionales también tuvo una etapa de baja porcentual que duró, al menos, hasta 1897, cuando se recupera de manera parecida a como lo hizo en la década de 1870.

¿Cómo se comportaron los componentes en la segunda etapa? En víspera de la reforma, los redactores del Boletín de Estadística, órgano de difusión de cifras oficiales, valoró el comportamiento de los ramos de las rentas estatales. Observaron el problema de establecer una imposición justa en el contexto de las oscilaciones del mercado internacional del henequén. ${ }^{51}$ Resultaba evidente que entre 1889 y 1894 el henequén aportaba un cuarto de la recaudación anual con independencia del precio de la fibra, y el comportamiento creciente de los derechos de consumo, que aportaba el $25 \%$, estaba asociado a la demanda de productos nacionales en la medida en que la devaluación afectaba a la importación de mercancías extranjeras y al consumo de las nacionalizadas. ${ }^{52}$ Pero no sólo la variabilidad del precio del henequén repercutía en la captación de recursos públicos, también la depreciación de la plata mexicana en el mercado por la emergencia del patrón oro. Si bien era cierto que el precio del henequén decrecía, su impacto era reducido por la «alta depreciación» de la plata nacional en el mercado exterior. ${ }^{53}$ Es decir, la devaluación del peso favorecía la compra del henequén en rama, tenía un efecto compensatorio. ${ }^{54}$

50 Luego del decreto del 30 de marzo de 1880, que ordenó nuevas manifestaciones de predios de nueva creación, se realizaron otras declaraciones por decretos subsiguientes del 6 de noviembre de 1883, 6 y 10 de diciembre de 1887, y orden del 1 de diciembre de 1901. Yucatán (1907: 261).

51 Boletín de Estadística, 16 de marzo de 1895.

52 Boletín de Estadística, 16 de abril de 1895. En efecto, después del crecimiento extraordinario del precio del henequén en 1888, su descenso entre 1889 y 1892 provocó una "gran rigidez monetaria» (Pérez Peniche 1893: 122). El sector interno respondía a cambios del sector externo, del mismo modo que los ingresos dependientes del consumo. Esta interdependencia entre sector externo-interno-ingreso público acuñó la idea expuesta en 1893 por el gobernador Daniel Traconis: «El estado de la Hacienda Pública no es más que el trasunto o reflejo de la situación económica de cada país, por cuya razón, a medida que ésta se modifica favorablemente, aquella marcha mejor [...].» (Pérez Peniche 1893: 125).

53 Pérez Peniche (1893: 127).

54 Rosenzweig ((1974a; 1974b: 866). En el ámbito fiscal de la federación, la desamortización de la plata no afectó a los ingresos federales, ya que se había liberado su comercio desde 1882. Tampoco el poder adquisitivo de las exportaciones nacionales entre 1889 y 1896 . El problema radicó en la conversión de la deuda pública sobre la nueva base oro, que generó una deuda flotante, y la devaluación del peso respecto al oro, que incrementó los riesgos entre 1895 y 1901 . La devaluación de la plata repercutió en el sistema fiscal y financiero, ya que todas las tasas y todos los impuestos se cobraban en plata, así como en la contracción de las importaciones (Carmagnani 2010: 371-373). 
En cuanto al impuesto predial de las fincas rústicas y urbanas, la base gravable registrada en el catastro carecía de cifras realistas. De acuerdo con los datos de la Tesorería General, en 1878 el valor estatal de la propiedad rural y urbana sujeta a contribución ascendía a 3.369 .315 pesos, incluyendo el incremento de un tercio de su valor para efectos de la recaudación fiscal de acuerdo con la ley del 5 de abril de $1870 .^{55}$ En 1890, algunos periodistas calculaban que el valor de los bienes raíces ascendía a 100 millones de pesos ${ }^{56}$ cuatro años después, los estadistas oficiales calcularon el monto estatal en 65 millones y el de la ciudad de Mérida en 14.765 .000 pesos; 50 millones su propiedad rústica henequenera y un millón las otras, incluyendo las salinas. ${ }^{57}$ Aunque existía una diferencia importante del 35\% entre una y otra estimación, ambos grupos denunciaban la ocultación de los valores. ${ }^{58}$ En consecuencia, el incremento en la recaudación de la contribución predial obedecía a la revaloración del catastro por decreto del 2 de abril de 1894, que en algunos casos quintuplicó el valor de las propiedades, sosteniendo la excepción de aquéllas situadas en la franja fronteriza con los indígenas rebeldes. ${ }^{59} \mathrm{Al}$ incremento por decreto correspondió una reducción de la tasa a pagar por millar que pasó del $15 \%$ a un módico $3 \%$.

¿Cuáles fueron los nuevos valores territoriales? La rural se evaluó en 2.202.400 pesos y la urbana en 2.211.477 pesos, lo que supone un valor total inferior a 4,5 millones de pesos. Y, para Mérida, los predios urbanos se valoraron en 1.625 .572 pesos y las fincas rurales en 473.909 pesos. ${ }^{60}$ Esto revela un pacto del gobierno con los hacendados para no incrementar el peso fiscal sobre el sector henequenero. Al respecto, los estadistas del Boletín comentaron que las cifras totales de la propiedad «resultaban una especie de sarcasmo.» ${ }^{61}$ Del mismo modo, al incremento en la base gravable le correspondió un menor porcentaje con el que contribuir: un 1,5\% las fincas rústicas y urbanas (en vez de un $3 \%$ a millar), y el $3 \%$ a las salinas. Aún más, en 1898 se cambió la tasa impositiva del $3 \%$ por una nueva del $1 \%{ }^{62}$

A partir de 1896, año de traslape con el nuevo régimen fiscal que liquidó los consumos, se observa que los recursos aportados por la nueva imposición a las ventas fueron muy débiles respecto a los robustos impuestos a los consumos

55 «Estado que manifiesta el número de fincas rústicas y urbanas de Yucatán», Mérida, 17 de agosto de 1878, en Expediente (1878: 48).

56 La Sombra de Cepeda, 27 de julio de 1890.

57 Boletín de Estadística, 1 de noviembre de 1894.

58 La Sombra de Cepeda, 27 de julio de 1890.

59 El incremento en cinco veces del valor de las propiedades tenía un efecto en los impuestos prediales y los derechos de traslación de dominio. Yucatán (1907: 261-262).

60 Boletín de Estadística, 16 de mayo de 1895.

61 Boletín de Estadística, 16 de mayo de 1895. No pretendían un realismo intachable, los estadistas sabían que en ninguna parte se cuantifica "con escrupulosa exactitud la riqueza real», pero el caso era que en ningún lugar como en Yucatán era «tan notable la ocultación». Boletín de Estadística, 1 de noviembre de 1894.

62 Zuleta (2006: 306). 


\section{GRÁFICO 4}

CAMBIO EN LA ESTRUCTURA TRIBUTARIA, 1883-1902

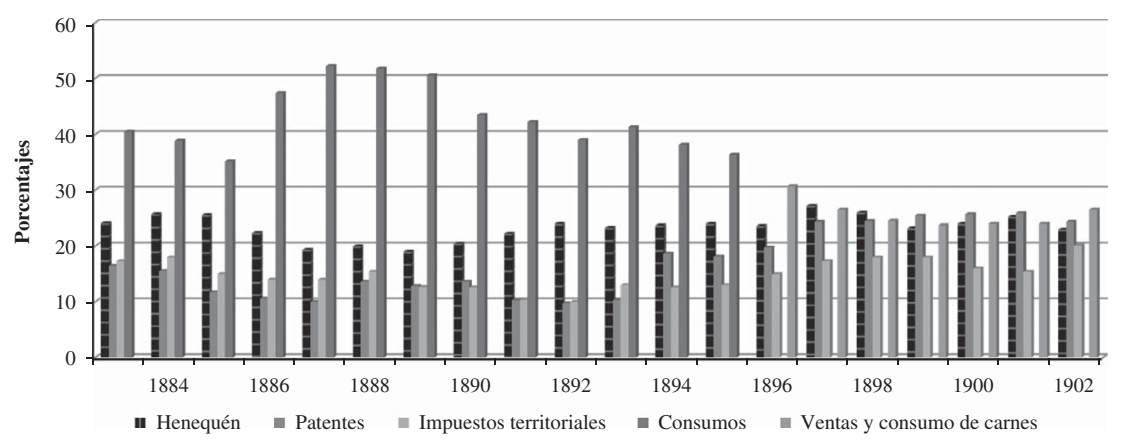

(ver Cuadro 6). En la etapa entre 1897 y 1902 no aportaron más que un modesto $17 \%$. En realidad, no sustituyeron los ingresos de consumos; pero prevaleció la alcabala de consumo de carnes, ya que su aportación rondaba alrededor del $10 \%$ y, a partir de 1896, fue en ascenso como el consumo principalmente- de ganado vacuno; de 1895 a 1902, el consumo de carnes creció en un promedio anual del $6 \%$. Pero ambas imposiciones indirectas no lograron proporcionar lo que rindieron los consumos en años anteriores.

\section{CONCLUSIONES}

En la transición de la fiscalidad del Antiguo Régimen hacia el liberalismo, los cambios en la estructura tributaria dependieron de los regímenes políticos, los pactos interoligárquicos y el peso de la tradición impositiva; pero, a partir de la segunda mitad del siglo XIX, los cambios estructurales en la demografía y economía de Yucatán tendieron a repercutir en la estructura de las rentas públicas y en los niveles de participación de los impuestos directos o indirectos. Durante el régimen liberal de Cádiz, encontramos una fuerte resistencia local para abolir el tributo indígena y suspender la subvención novohispana. Ante el desafío, desde 1814 la respuesta yucateca logró un equilibrio entre impuestos procedentes del comercio y la capitación (Sánchez Santiró: 2012). Pero esa relación no prevaleció en el Yucatán independiente, donde la capitación representó más del $60 \%$ de las rentas. Y se observa que, durante los años de mayor apertura mercantil (1841 y 1846), los ingresos derivados del comercio externo tuvieron una participación equilibrada respecto de la capitación. Sin embargo, la guerra de castas con sus efectos de desarticulación demográfica, pérdida de tributarios y destrucción de bienes territoriales empujó a introducir impuestos directos de patentes sobre el comercio y la industria, así como la contribución predial 
GRÁFICO 5

TENDENCIA DE LA RENTA PÚBLICA DE YUCATÁN, 1851-1902

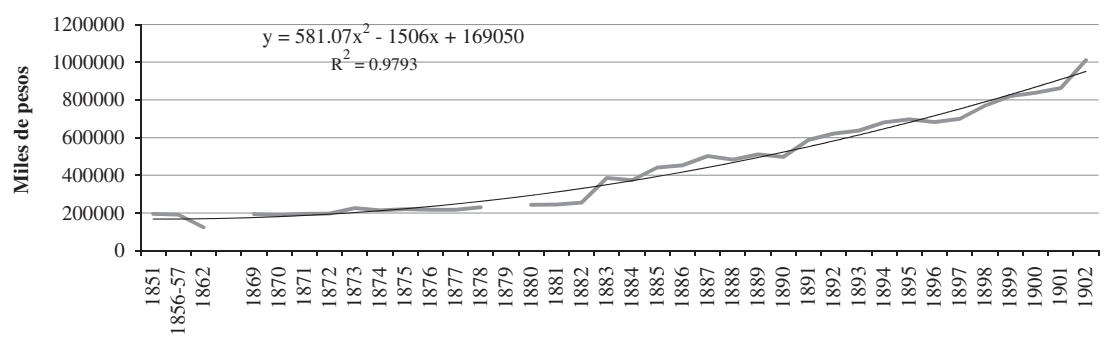

Nota: la fuente corresponde a los datos de los Cuadros 1, 2 y 4 procesados en Excel, con una línea de tendencia polinómica.

sobre bienes inmuebles de manera precaria. En esta etapa (1850-1862) hubo un giro hacia la tributación directa, sin la capitación, que rindió el $63 \%$ en promedio anual para el ciclo. Pero en la coyuntura del inestable Segundo Imperio y de la campaña contra los indígenas rebeldes, la centralización imperial incrementó sus ingresos un $78 \%$ a partir de impuestos al comercio exterior (importación) e interior (circulación y consumo). ${ }^{63}$

De manera que, a partir de 1869, los impuestos al consumo, hasta su abolición en 1896, fueron las fuentes más caudalosas de ingreso, protegiendo el crecimiento de la producción henequenera como sector de exportación en la etapa de modernización. Este cambio profundo en la estructura económica de Yucatán favoreció adoptar una moderna fiscalidad en dos momentos: en 1883, cuando se introduce el moderno impuesto directo a la producción de fibra, y en 1896, año en que se abandonan los impuestos al consumo en favor de los indirectos sobre las ventas. Con el cambio en la estructura económica, la cultura fiscal modelada por la práctica dio como resultado una exitosa combinación de impuestos que redistribuyó de manera equilibrada la carga fiscal entre los sectores productivos que, por lo pronto, duró hasta 1902.

La tendencia de las rentas públicas de Yucatán durante el ciclo 1850-1902 muestra dos grandes periodos: uno entre 1850 y 1882 caracterizado por un lento crecimiento y una recuperación de volumen de ingresos anteriores a la guerra de castas y a la separación de Campeche; y otro entre 1883 y 1902 cuando, con el impuesto del henequén, la renta dio un salto del $51 \%$ respecto

63 Como ya se dijo, la subvención cubrió la campaña contra los mayas rebeldes. Desde el inicio de la guerra de castas, las autoridades recurrieron con frecuencia a donaciones "voluntarias», préstamos forzosos, incautación de productos y bienes particulares, así como de capitales, para satisfacer las urgencias del día (Suárez Molina, (1977: vol. 2, 110-112). 
a 1882, con un crecimiento acumulado superior al $153 \%$. Así que fue un éxito en la medida en que en años de depreciación los contribuyentes pagaban una carga soportable, pero en los años de bonanza, se aligeraba. Sin duda, el impuesto directo a la producción del henequén agregado a la parte proporcional del modesto impuesto predial a las haciendas productoras se convirtió en fuente central del erario yucateco, ${ }^{64}$ principalmente después del ajuste al catastro en 1894. Pero el impuesto a la fibra de henequén en sus mejores años aportó no más del $25 \%$ de la renta anual del estado.

En cuanto a los cambios en la estructura de las rentas entre 1850 y 1862 (véase Gráfico 4), la tributación directa tenía mayor aportación, un desempeño combinado de impuestos tradicionales como las contribuciones personales y los de corte moderno como las patentes, así como el impuesto a las «rentas» de los capitales en fincas rústicas, urbanas y charcos de sal. Éste último pronto fue sustituido por el impuesto predial que, a corto plazo participó con un $18 \%$, en los recursos públicos de 1862. En cambio, los indirectos empezaron a rendir menos, como las aduanas terrestres y, posteriormente, se sobreponen para ofrecer una aportación regular del $16 \%$ a las rentas yucatecas.

Con el restablecimiento de la República, la tendencia histórica para la serie de datos de rentas públicas de 1869 a 1902 (ver Gráfico 5) muestra el cambio en la estructura tributaria en tres etapas:

1. 1869-1882: muestra una tendencia tradicional con una fuerte aportación de los impuestos indirectos del consumo y la introducción del impuesto predial de carácter moderno, pero negociado con los propietarios influyentes. La curva de los impuestos al consumo muestra crecimiento de 1869 a 1874, seguido de una tendencia oscilante entre años de baja recaudación y recuperación estacional, pero a largo plazo las rentas por consumo van perdiendo participación a partir de 1889.

2. 1883-1896: se caracteriza por una primera etapa entre 1883 y 1893 , en la que comienza un ciclo de pérdida de recursos por consumo al tiempo que se introduce una nueva imposición directa, pero de carácter tradicional por imponer teóricamente la producción bruta de la fibra del henequén; no obstante, los consumos se recuperaron entre 1886 y 1890 , en tanto que los directos del predial y las patentes de un estancamiento vinieron a menos. La segunda etapa de transición entre 1893 y 1896 comienza con un declive en la recaudación por consumo hasta su eliminación, combinado con los impuestos directos de carácter moderno como las patentes que gravaron al sector urbano (secundario y terciario) con una participación no distante del impuesto al sector agrario del henequén hasta lograr definir el tercer periodo:

64 El agregado de la contribución predial de las fincas rústicas dificulta aislar la henequenera para valorar en conjunto la aportación del henequén a las rentas estatales. 
3. 1897-1902: los impuestos de patentes de carácter urbano o del sector primario y secundario alcanzaron un protagonismo porcentual mayor en las rentas públicas anuales del Estado. Por su parte, los nuevos impuestos indirectos de ventas (al mayoreo, al menudeo y ambulantes) no fueron determinantes para el ingreso estatal; sólo considerándolos agregados a las alcabalas tradicionales a la matanza de ganados, ambos pudieron responder moderadamente a la supresión de los impuestos al consumo.

De manera que, en este periodo, emergió el modelo fiscal para el estado de Yucatán, caracterizado por un equilibrio en la imposición directa urbana (patentes) y agrícola (henequenera, básicamente) con el soporte de otros ramos indirectos (ventas y carnes) y directos (predial y traslación de dominio). En este periodo, los impuestos muestran cualidades de moderación; en otros, de una recaudación discreta, y, entre los más robustos, una distribución equilibrada entre los directos del sector agrario y los directos del sector secundario y terciario.

\section{FUENTES}

Archivo General del Estado de Yucatán (AGEY), Mérida.

Biblioteca Virtual de Yucatán (BVY), Mérida.

Yucatán, Boletín de Estadística, Mérida, 1894-1903.

Yucatán, La Razón del Pueblo, Mérida, 1878-1882, 1886-1888, 1901.

Yucatán, La Sombra de Cepeda, Mérida, 1890.

Yucatán, La Unión Liberal, Mérida, 1856-1857.

\section{BIBLIOGRAFÍA}

AвEndroth, H. H. (2006): «La desigual tributación directa en Bolivia, 1825-1872: indios sí, criollos no», en L. Jáuregui (coord.) (2006), De riqueza e inequidad. El problema de las contribuciones directas en América Latina, siglo XIX. México: Instituto Mora, pp. 79-113.

Anuario estadístico de la república mexicana 1895 formado por la Dirección General de Estadística a cargo del Dr. Antonio Peñafiel (1896). México: Oficina de la Secretaría de Fomento.

Askinasy, S. (1936): El problema agrario de Yucatán. México: Ediciones Botas.

CAmpos García, M. (2013): "Que los yucatecos todos proclamen su independencia». (Historia del secesionismo en Yucatán, 1821-1849). Mérida: Ediciones de la Universidad Autónoma de Yucatán.

Carmagnani, M. (1989): «El liberalismo, los impuestos internos y el Estado federal mexicano, 1857-1911». en Historia Mexicana XXXVIII (3), pp. 471-496.

CARMAGnani, M. (1994): Estado y mercado. La economía pública del liberalismo mexicano, 1850-1911. México: El Colegio de México / Fondo de Cultura Económica.

Carmagnani, M. (2010): «La economía pública del liberalismo. Orígenes y consolidación de la hacienda y del crédito público, 1857-1911», en S. Kuntz Ficker (coord.) (2010), 
Historia económica general de México. De la colonia a nuestros días. México: El Colegio de México / Secretaría de Economía, pp. 353-376.

СовÁ NOH, L. (2009): El «indio ciudadano». La tributación y la contribución personal directa en Yucatán, 1786-1825. México: Universidad Autónoma de Yucatán / Instituto Mora.

Colección de leyes, decretos, órdenes o acuerdos de tendencia general del Poder Legislativo del Estado Libre y Soberano de Yucatán. Formada por Alonso Aznar Pérez (1851). Mérida: Imprenta R. Pedrera, t. 3.

Colección de leyes, decretos, órdenes y demás disposiciones de tendencia general expedidas por el Poder Legislativo del Estado de Yucatán, formada con autorización del gobierno por Eligio Ancona (1882). Mérida: Imprenta de «El Eco de Comercio», t. 1.

Comín, F. (1966): Historia de la hacienda pública 1. Europa. Barcelona: Crítica, pp. 46-48.

CONTRERAS, C. (2006): «Las contribuciones directas en la formación del Perú republicano», en L. Jáuregui (coord.) (2006), De riqueza e inequidad. El problema de las contribuciones directas en América Latina, siglo XIX. México: Instituto Mora, pp. 123-148.

Documentos justificativos de la memoria que el c. Antonio G. Rejón presentó a la legislatura de Yucatán como secretario general del gobierno del estado de Yucatán, en 6 de setiembre de 1862 (1862). Mérida: Imprenta de J. D. Espinosa.

Cosío Villegas, D. (1974): Historia moderna. El Porfiriato. La vida económica. México: Editorial Hermes, t. 2.

Dumond, D. E. (2005): El machete y la cruz. La sublevación campesina en Yucatán. México: Universidad Nacional Autónoma de México.

Estadística de Yucatán (1853). México: Sociedad de Geografía y Estadística.

Expediente de la visita oficial del estado hecha por el c. José María Iturralde, vice-gobernador constitucional del mismo, en cumplimiento del artículo 56 de la Constitución Política de Yucatán (1878). Mérida: Tipografía de G. Canto.

Expediente de la visita oficial del estado hecha por el c. lic. Manuel Cirerol, vicegobernador constitucional del mismo en cumplimiento del artículo 56 de la Constitución política de Yucatán (1869). Mérida: Imprenta del Gobierno a cargo de M. Heredia Argüelles.

Exposición del gobierno de Yucatán al supremo de la Unión sobre reconocimiento y amortización de los créditos del estado y sobre la necesidad de terminar la guerra de los indios para que esta península no se pierda para sí y para la república (1868) Mérida: Imprenta de J. D. Espinosa e Hijos.

Fuentes Quintana, E. (1990): «El estilo tributario latino», en Las reformas tributarias en España. Teoría, historia y presupuestas. Edición cuidada por Francisco Comín. Barcelona: Crítica, pp. 353-450.

García Quintanilla, A. (1986): «Del $k i$ al henequén: génesis de un lugar social (1850-1915), en Los tiempos en Yucatán. Los hombres, las mujeres y la naturaleza (siglo XIX). México: Claves Latinoamericanas, pp. 17-97.

HinRICHS, H. H. (1967): Una teoría general del cambio de la estructura tributaria durante el desarrollo económico. México: Centro de Estudios Monetarios Latinoamericanos.

Iniciativa sobre el arreglo y economías de la Hacienda Pública del Estado de Yucatán, presentada a su Legislatura en 3 de abril de 1850, por los diputados que la suscriben (1850). Mérida: Imprenta de R. Pedrera.

IrIGOIN, M. A. (2006): «Ilusoria equidad. La reforma de las contribuciones directas en Buenos Aires, 1850», en L. Jáuregui (coord.) (2006), De riqueza e inequidad. El problema de las contribuciones directas en América Latina, siglo XIX. México: Instituto Mora, pp. 47-77.

JÁUREGUI, L. (coord.) (2006): De riqueza e inequidad. El problema de las contribuciones directas en América Latina, siglo XIX. México: Instituto Mora. 
(2006): «De Re Tributaria. ¿Qué son las contribuciones directas?», en L. Jáuregui (coord.) (2006), De riqueza e inequidad. El problema de las contribuciones directas en América Latina, siglo XIX. México: Instituto Mora, pp. 9-21.

Joseph, G. M. (1992): Revolución desde afuera: Yucatán, México y los Estados Unidos, 1880-1924. México: Fondo de Cultura Económica.

KunTz FickeR, S. (2014): «La contribución económica de las exportaciones en México: un acercamiento desde las finanzas estatales, 1880-1926», en América Latina en la Historia Económica/Latin America in Economic History 21 (2), mayo-agosto, pp. 7-39.

Kuntz Ficker, S. (coord.) (2010): Historia económica general de México. De la colonia a nuestros días. México: El Colegio de México / Secretaría de Economía.

Lapointe, M. (2008): Historia de Yucatán. Siglos XIX-XXI. Mérida: Ediciones de la Universidad Autónoma de Yucatán.

Memoria del estado que guarda la administración pública de Yucatán, escrita por el secretario general de gobierno c. Antonio G. Rejón, y leída por el mismo ante la legislatura constitucional, en la sesión del día 8 de setiembre de 1862 (1862). Mérida: Imprenta de J. D. Espinosa.

Memoria leída ante el Augusto Congreso Extraordinario de Yucatán, por el secretario general de gobierno, el día 18 de setiembre de 1846 (1846). Mérida: Imprenta de Castillo y Compañía.

Memoria leída ante el Honorable Congreso del Estado Libre de Yucatán por el secretario de gobierno en 20 de julio de 1857 (1857). Mérida: Tipografía a cargo de Mariano Guzmán.

Memoria leída en la solemne instalación de la Undécima Legislatura Constitucional, verificada el 1 de enero de 1886 por el c. gobernador del estado libre y soberano de Yucatán, general Octavio Rosado (1885). [sic] Mérida: Imprenta de "El Eco de Comercio».

Memoria leída por el c. Gobernador del estado libre y soberano de Yucatán, general Octavio Rosado, en la solemne instalación de la Décima Legislatura Constitucional, verificada el 1 de enero de 1884 (1884). Mérida: Imprenta de Echánove y López.

Memorias de estadísticas remitidas por el gobierno de Yucatán a la Cámara de Senadores del Soberano Congreso General (1826). Mérida: Imprenta de la Federación Mexicana en Palacio.

Mensaje leído por el c. gobernador constitucional, lic. Manuel Cirerol, en la solemne apertura del último periodo de sesiones de la Tercera Legislatura del Estado de Yucatán, el 1 de julio de 1871 (1871). s. p. i.

Memoria presentada al A. Congreso del Estado de Yucatán por el secretario general de gobierno en 29 y 30 de setiembre de 1841 (1841). Mérida de Yucatán: Imprenta de José Dolores Espinosa.

Memoria presentada por el secretario del gobierno de Yucatán a las Cámaras del H. Congreso, en los días 10 y 11 de enero de 1851 (1851). Mérida: Tipografía de R. Pedrera.

Orosa Díaz, J. (1956): Legislación henequenera en Yucatán (1833-1955). Mérida: Ediciones Fomento de Yucatán.

PaYno, M. (1868): Cuentas, gastos, acreedores y otros asuntos del tiempo de la intervención francesa y del imperio. México: Imprenta de Ignacio Cumplido.

Pérez Peniche, R. (1893): Reseña histórica de la administración del c. coronel Daniel Traconis, gobernador constitucional del estado de Yucatán, 1890 a 1892. Mérida: Imprenta «Gamboa Guzmán».

ReEd, N. A. (2001): The Caste War of Yucatán. Revised Edition. California: Stanford University Press.

Reseña de la marcha de los diversos ramos de la Hacienda Pública durante el ejercicio fiscal de 1898, que presenta al gobierno del estado el Tesorero General c. José M. Iturralde (1899). Mérida: Imprenta de «La Revista de Mérida». 
Reseña de la marcha de los diversos ramos de la Hacienda Pública durante el ejercicio fiscal de 1899, que presenta al gobierno del estado el tesorero general c. José M. Iturralde (1900). Mérida: Imprenta Gamboa Guzmán.

Reseña de las operaciones de la Tesorería General del Estado correspondiente al año fiscal de 1900 (1901). Mérida: Imprenta «Pérez Ponce».

Rosenzweig, F. (1974a): «El comercio exterior», en D. Cosío Villegas (1974), Historia moderna. El Porfiriato. La vida económica. México: Hermes, t. 2, pp. 635-729.

Rosenzweig, F. (1974b): «Monedas y bancos», en D. Cosío Villegas (1974), Historia moderna. El Porfiriato. La vida económica. México: Hermes, t. 2, pp. 789-885.

SANChÉz SANTIRó, E. (2006): «La fiscalidad directa en el México decimonónico: el caso de la contribución rústica (1835-1846)», en L. Jáuregui (coord.), De riqueza e inequidad. El problema de las contribuciones directas en América Latina, siglo XIX. México: Instituto Mora, pp. 225-249.

SANChÉZ SANTiRó, E. (2008): «Ingresos fiscales y economía en México, 1790-1910», ponencia en IX Congreso Internacional de la Asociación Española de Historia Económica, Murcia, 9-12 de septiembre, 30 pp.

SANChÉz SANTiRó, E. (2009): Las alcabalas mexicanas [1821-1857]. Los dilemas en la construcción de la Hacienda nacional. México: Instituto Mora.

SANChÉz SANTIRó, E. (2012): «Los impactos fiscales de una guerra distante: crisis y restauración de la Real Hacienda en la Provincia de Yucatán (1801-1821)», en Revista de Historia Económica / Journal of Iberian and Latin American Economic History 30 (3), pp. 323-352.

SANTILLI, D. V. (2010): «El papel de la tributación en la formación del Estado. La contribución directa en el siglo XIX en Buenos Aires», en América Latina en la Historia Económica 17 (1), pp. 31-63.

SEguRA, J. S. (1863): Boletín de leyes del Imperio Mexicano, o sea código de la restauración. México: Imprenta Literaria, t. 1.

Serrano Ortega, J. A. (2006): "Contribuciones directas y reformas fiscales en las regiones de México, 1820-1836», en L. Jáuregui (coord.) (2006), De riqueza e inequidad. El problema de las contribuciones directas en América Latina, siglo XIX. México: Instituto Mora, pp. 183-224.

Serrano Ortega, J. A. (2007): Igualdad, uniformidad, proporcionalidad. Contribuciones directas y reformas fiscales en México, 1810-1846. México: Instituto Mora.

SuÁrez Molina, V. (1977): Evolución económica de Yucatán a través del siglo XIX. México: Ediciones de la Universidad Autónoma de Yucatán, t. 1.

Tesorería General de Yucatán. Estado que demuestra los rendimientos y egresos de [1]832 (1833). Mérida: s. i.

Uнtноғғ, L. M. (2004): «La difícil concurrencia fiscal y la contribución federal, 1861-1924. Notas preliminares», en Historia Mexicana LVI, pp. 129-178.

Vallejo Pousada, R. (ed.) (2008): Los tributos de la tierra. Fiscalidad y agricultura en España (siglos XVII-XX). España: Publicacions de la Universitat de València.

Yucatán 1902-1906 (1907). Mérida: Imprenta «Gamboa Guzmán».

Zuleta Miranda, M. C. (1995): «El federalismo en Yucatán: política y militarización (1840-1846)», en Secuencia 31, pp. 23-49.

Zuleta Miranda, M. C. (2004): «Hacienda pública y exportación henequenera en Yucatán, 1880-1910», en Historia Mexicana LIV (1), pp. 179-247.

Zuleta Miranda, M. C. (2006): De cultivos y contribuciones. Agricultura y Hacienda Estatal en México en la "Época de la Prosperidad». Morelos y Yucatán 1870-1910. México: Universidad Autónoma Metropolitana. 